\title{
O PROTAGONISMO ESTUDANTIL NA EXTENSÃO UNIVERSITÁRIA: A EXPERIÊNCIA DO NÚCLEO DE ATUALIZAÇÃO PÚBLICA NA UNIVERSIDADE FEDERAL DO CARIRI
}

\section{STUDENT PROTAGONISM IN THE UNIVERSITY EXTENSION: THE EXPERIENCE OF THE PUBLIC UPDATE CENTER IN THE FEDERAL UNIVERSITY OF CARIRI}

\author{
Estêvão Lima Arrais* \\ ORCID: https://orcid.org/0000-0002-5484-3244 \\ Jessica Monteiro Ferreira** \\ ORCID: https://orcid.org/0000-0003-0749-8430 \\ Jeferson Antunes*** \\ ORCID: https://orcid.org/0000-0002-2969-5788
}

\begin{abstract}
Resumo
O presente estudo consiste em descrever a experiência de estudantes no processo de gestão do Núcleo de Atualização Pública (NAP) da Universidade Federal do Cariri (UFCA), proposto apenas por estudantes, possibilitado pelo programa de protagonismo estudantil (PROPE). Através da observação participante, utilizando-se do relato holístico, apresenta-se o processo de criação, gestão e integração do NAP ao cotidiano acadêmico. A modalidade PROPE se mostrou inovadora, por atribuir a estudantes a possibilidade de submissão de projetos de extensão, fomentando o protagonismo estudantil, mesmo que mediado. Para isso, o acolhimento de professores e professoras foi essencial, o que permitiu atividades de planejamento, gestão e avaliação da atividade de extensão, contribuindo para a formação de estudantes, em que o projeto de extensão foi fundamental para despertar o desejo pelas áreas de planejamento e gestão de projetos.
\end{abstract}

Palavras-chave: Protagonismo estudantil; Administração pública; Ensino superior.

\begin{abstract}
This study describes the experience of students in the Public Update Center (NAP) management process at the Federal University of Cariri (UFCA), proposed only by students, and made possible by the student protagonism program (PROPE). Through participant observation, using holistic reporting, the process of creating, managing and integrating NAP into the academic life is presented. The PROPE modality was innovative, providing students with the possibility of submitting extension projects, valuing mediated student leadership. To accomplish these tasks, the reception of male and female professors was essential, which allowed activities of planning, management and evaluation of the extension activity, contributing to the training of students, in which the extension project was fundamental to awaken their desire for the areas of planning and project management.
\end{abstract}

Keywords: Student leadership; Public administration; Higher education.

Data recebimento: $13 / 09 / 2020$

Data de aceite: $05 / 04 / 2021$
* Aluno de Doutorado da Universidade Estadual do Ceará (UECE), Fortaleza - CE, Brasil. E-mail: estevaolarrais@gmail.com

** Graduação. Universidade Federal do Cariri (UFCA), Juazeiro do Norte - CE, Brasil. E-mail: jssicam7@gmail.com

*** Aluno de Doutorado da Universidade Federal do Ceará (UFC), Fortaleza-CE, Brasil. E-mail: cat_kalderash@hotmail.com 


\section{Introdução}

O ensino na área de Administração Pública tem passado por inúmeras metamorfoses. A mais recente se consolida com a aprovação da Resolução No 1 , de 13 de janeiro de 2014, também denominada de Diretrizes Curriculares Nacionais (DCN) do Campo de Públicas: um espaço formado por estudantes, professores, professoras, pesquisadores, pesquisadoras e profissionais que defendem a profissionalização da gestão pública em conformidade com a ética republicana e os princípios democráticos (PIRES, 2014).

Este novo campo de conhecimento é formado pelos cursos de bacharelado em Administração Pública, Gestão Pública, Políticas Públicas, Gestão Social, Ciências do Estado e Gestão de Políticas Públicas, fortemente caracterizados por formações técnico-políticas e multidisciplinares, sendo uma área autônoma do campo da Administração (DCN, 2014). A formação do Campo de Públicas foi fruto de muitos debates e militâncias em eventos e reuniões nacionais nas quais ressaltavam que a Administração muitas vezes se encontrava apartada de temáticas relacionadas à gestão governamental e sociedade civil, gerando não apenas hiatos de representatividade, mas também de formação (PIRES, 2014).

Estes cursos mesclam a multidisciplinariedade promovida pelos espaços universitários, constituída por docentes de diversas áreas, e pelas necessidades de gestores, gestoras, técnicas e técnicos com formação jurídica, administrativa e política capazes de ocupar espaços estratégicos, diretivos e operacionais no interior do Estado. Todavia, apesar do grau de complementariedade, as relações entre a multidisciplinariedade e a formação técnico-jurídica frequentemente é também conflituosa (COELHO, 2006), não gerando necessariamente um processo transdisciplinar, mas, antes, um processo de sobreposição disciplinar.

A Universidade Federal do Cariri (UFCA) foi fundada pela Lei $\mathrm{n}^{\circ} 12.826$, de 5 de junho de 2013, formada por cinco campi no Ceará nas cidades de Juazeiro do Norte, Crato, Barbalha, Icó e Brejo Santo, com aproximadamente 2.064 alunos matriculados, dos quais $62 \%$ são oriundos de escolas públicas. A referida universidade é oriunda do Programa de Apoio a Planos de Reestruturação e Expansão das Universidades Federais (REUNI), fruto de seu desmembramento da Universidade Federal do Ceará (UFC) (ANTUNES et al., 2015).

Com as diretrizes do REUNI, que permitiam a criação de cursos inovadores capazes de suprimir demandas locais, surge o curso de Administração Pública. Este curso justifica sua existência no contexto de mudanças das atribuições das organizações do Estado, do Mercado e da Sociedade Civil e que agora - dados os fenômenos como a globalização e outras complexidades - precisam de um maior nível de cooperação e de articulação entre os/as agentes destes setores, especialmente no âmbito local e regional (ANTUNES et al., 2015).

A primeira turma do curso de Administração Pública da UFCA é datada de 2011, período em que as discussões sobre o Campo de Públicas eclodiram em todo o Brasil, não se limitando apenas ao eixo Sul/Sudeste. Com isso, paulatinamente, discentes, professoras e professores iniciaram um engajamento em grandes eventos nacionais, tais como o Encontro Nacional dos Estudantes de Administração Pública (ENEAP); e em organizações represen- 
tativas como a Federação Nacional dos Estudantes de Administração Pública (FENEAP), que - após a aprovação das DCNs - foram modificados para Encontro Nacional dos Estudantes do Campo de Públicas (ENECAP); e Federação Nacional dos Estudantes do Campo de Públicas (FENECAP), respectivamente.

Com essa troca permanente de experiência, especialmente por parte dos/das discentes, um pequeno grupo de estudantes de Administração Pública da UFCA percebeu o quão abrangente são as discussões do Campo de Públicas, além de reconhecerem que cada curso de bacharelado no Brasil detinha um conjunto de particularidades. Visto que o curso de Administração Pública era tão recente quanto a própria UFCA, tornava-se improvável a ampliação dos debates nos espaços de ensino, dado que já estavam alinhados às disciplinas do próprio programa pedagógico do curso e ao número reduzido de docentes, dificultando ainda mais a possibilidade de ampliar o debate sobre certas áreas.

Concomitante a estes eventos, a Pró-Reitoria de Extensão (PROEX/UFCA) inovou em 2017, ao implementar uma nova modalidade extensionista: a linha de Protagonismo Estudantil (PROPE). Diferente dos demais projetos de extensão, o novo edital permitia agora que estudantes da UFCA - ainda na graduação - propusessem projetos de extensão diretamente vinculados ao Programa Institucional de Extensão (PIEs), que se caracterizam como "ações de extensão vinculadas à PROEX/UFCA com caráter permanente e que possuem a função de promover conhecimento crítico e social para o desenvolvimento regional sustentável" (UFCA, 2020).

Os PIEs, à época, eram vinculados com as seguintes áreas principais: Saúde, Tecnologia, Trabalho, Meio Ambiente, Cultura, Comunicação, Educação e Direitos Humanos; e possuíam as seguintes linhas temáticas secundárias: Agroecologia, Sustentabilidade e Tecnologias Socioambientais; Ciência, Educação e Interdisciplinaridade; Educação e Ações Afirmativas; Saúde e Qualidade de Vida; e Trabalho, Renda e Economia Solidária.

Diante das novas possibilidades ofertadas pela PROEX/UFCA, por meio da modalidade PROPE, e objetivando atender às necessidades de formações suplementares existentes no Campo de Públicas no curso de Administração Pública da própria universidade, foi proposto o projeto denominado Núcleo de Atualização Pública (NAP). A partir desse contexto, o objetivo deste artigo consiste em descrever a experiência dos estudantes no processo de gestão do NAP.

Inicialmente, a pesquisa descreverá o edital unificado 01/2017 (PROEX/UFCA), que versa exclusivamente sobre a modalidade Protagonismo Estudantil (PROPE). Espera-se, com este objetivo específico, que leitores e leitoras possam compreender o que é protagonismo estudantil à luz do próprio edital e de que modo o edital é operacionalizado.

Após a conceituação e explicação do edital, o artigo descreverá como ocorreu o processo de planejamento e gestão do NAP por estudantes gestores. Por fim, apresentam-se, através de relato holístico, as percepções de estudantes (proponente e bolsista) inseridos no projeto. 


\section{Metodologia}

Para o presente estudo, foi utilizada a observação participante do processo, em que o/a pesquisador/a participa diretamente do experimento proposto, interagindo com os participantes (FLICK, 2009). O método foi escolhido pelo interesse em observar as interações e os processos gerados, em que se focalizou a atenção nos possíveis processos e problemas que aparecem durante a investigação. As observações foram sistematizadas por meio de relatórios, onde foi tecida uma narrativa dos principais acontecimentos, por meio de relato holístico, que apresenta o relato de múltiplas perspectivas e a identificação de múltiplos fatores que emergem do quadro mais amplo (CRESWELL, 2010).

\section{O protagonismo estudantil (PROPE) sob a ótica da PROEX/UFCA - análise do Edital $01 / 2017$}

O Edital PROPE tratado nesta pesquisa se encontra no Edital Unificado $\mathrm{N}^{\circ} 01 / 2017$ da PROEX/UFCA. Nele, foram concebidas 331 bolsas remuneradas e 393 bolsas voluntárias, sendo direcionadas 30 bolsas para projetos propostos pelos estudantes de graduação na modalidade PROPE. O programa define-se como inovador por submeter uma chamada pública de seleção voltada unicamente para estudantes, reconhecendo seu protagonismo e efetivando a dialogicidade entre os quatro pilares (ensino, extensão, pesquisa e cultura) da Universidade Federal do Cariri (UFCA, 2020).

O Edital Unificado 01/2017 atribui ao PROPE o objetivo de fortalecer o protagonismo estudantil no espaço universitário, por meio da participação em projetos de extensão, além de contribuir para o processo de formação dos estudantes de graduação, facilitando a interação entre discentes, tutoras e tutores. Além destes elementos, busca também ampliar a efetivação do princípio institucional da indissociabilidade entre ensino, pesquisa, extensão e cultura (UFCA, 2020).

O planejamento e gerenciamento do Edital 01/2017 se deu por meio de uma gestão integrada entre as Pró-Reitorias de Ensino (PROEN); Pesquisa, Pós-Graduação e Inovação (PRPI); Extensão (PROEX); e Cultura (PROCULT), sendo também a seleção dos seus programas realizada de forma unificada, por meio deste instrumento. Docentes, técnicos, técnicas e discentes da UFCA puderam realizar submissão de projetos, mas atribuíam exclusividade (ou protagonismo) ao estudante para a submissão de ações nas modalidades PROPE e Ações Culturais (PROCULT/UFCA). 
Tabela 1: Distribuição de bolsas do Edital 01/2017.

\begin{tabular}{|c|c|c|c|c|c|}
\hline DIMENSÃO & MODALIDADE & $\begin{array}{l}\text { QUANTIDADE. } \\
\text { REMUNERADAS }\end{array}$ & \begin{tabular}{|l} 
QUANTIDADE \\
VOLUNTÁRIAS
\end{tabular} & CH SEMANAL & VIGÊNCIA \\
\hline \multirow[t]{2}{*}{ Extensão } & $\begin{array}{l}\text { Ampla } \\
\text { Concorrência }\end{array}$ & 85 & 170 & 12 & $\begin{array}{l}\text { Março a } \\
\text { dezembro/2017 }\end{array}$ \\
\hline & $\begin{array}{l}\text { Protagonismo } \\
\text { Estudantil } \\
\text { (PROPE) }\end{array}$ & 10 & 20 & 12 & $\begin{array}{l}\text { Março a } \\
\text { dezembro/2017 }\end{array}$ \\
\hline Cultura & Ações Culturais & 33 & 0 & 12 & $\begin{array}{l}\text { Março a } \\
\text { dezembro/2017 }\end{array}$ \\
\hline Ensino & $\begin{array}{l}\text { Programa de } \\
\text { Iniciação à } \\
\text { Docência (PID) }\end{array}$ & 64 & 64 & 12 & $\begin{array}{l}\text { Março a } \\
\text { dezembro/2017 }\end{array}$ \\
\hline Pesquisa & $\begin{array}{l}\text { Programa } \\
\text { Institucional de } \\
\text { Iniciação } \\
\text { Científica e } \\
\text { Tecnológica } \\
\text { (PIICT) }\end{array}$ & 119 & 119 & 8 ou 12 & $\begin{array}{l}\text { Agosto/2017 a } \\
\text { julho/2018 }\end{array}$ \\
\hline Integração & $\begin{array}{l}\text { Integração } \\
\text { Ensino- } \\
\text { Extensão } \\
(\text { PEEX) }\end{array}$ & 20 & 20 & 12 & $\begin{array}{l}\text { Março a } \\
\text { dezembro/2017 }\end{array}$ \\
\hline
\end{tabular}

Fonte: PROEX (2017).

Para a execução deste edital, todos os recursos das bolsas referidas foram disponibilizados a partir do orçamento da UFCA, exceto parte das bolsas do programa PIBIC, que foram financiadas por órgãos externos de fomento à pesquisa. A aprovação dos projetos submetidos à modalidade PROPE se deu a partir dos seguintes critérios avaliativos (UFCA, 2020):

1. Há interação com o público externo na elaboração da proposta, na geração de demanda e na realização das atividades?

2. A proposta apresenta informações sobre o público externo envolvido na ação e este é adequado para a atividade de extensão?

3. Como pode ser avaliado o potencial da proposta em gerar impacto e transformação social?

4. A metodologia é adequada e está coerente com os objetivos indicados no documento?

5. A ação se relaciona com as áreas da cultura, ensino e pesquisa? O processo de avaliação é participativo, são utilizados indicadores e envolve todos os participantes neste processo?

6. O referencial teórico é atualizado e apropriado à proposta? Está anexa a declaração do município, órgão ou comunidade atendida, demonstrando interesse no desenvolvimento da ação de extensão proposta ou justificativa da não aplicação do quesito?

7. Na metodologia proposta, há predomínio de atividades de cunho extensionista?

8. Há potencial de articulação com a linha temática do PIE indicada pelo proponente? 
Coube a estudantes interessados e interessadas desenvolverem os seguintes pontos encontradas no formulário de cadastro: 1) qual a área temática que o projeto estaria vinculado 2) potenciais parceiros e municípios onde as atividades poderão ocorrer; 3) qual o públicoalvo que se deseja atingir e qual a quantidade esperada; 4) resumo da ação de extensão; 5) justificativas do projeto; 6) quais os objetivos e metas do projeto; 7) fundamentação teóricometodológica que fundamente as estratégias a serem utilizadas no processo de operacionalização; 8) métodos para a implementação; e 9) instrumentos avaliativos das atividades.

\section{NAP: planejamento e gestão pela ótica dos estudantes gestores}

Com o projeto aprovado, foi iniciado o planejamento das atividades. No cronograma, estavam previstas as seguintes ações: 1) minicursos semanais todas às terças-feiras, norteados por temas mensalmente diferenciados; 2) realização do evento "Encontro com Gestores", atividade mensal que possibilitaria a troca de experiência de gestores públicos atuantes na máquina estatal; 3) o evento "Figura Pública", de periodicidade trimestral, almejando apresentar grandes personalidades históricas e contemporâneas para a gestão pública brasileira; e, por fim, 4) a criação do Núcleo de Estudos em Administração Pública (NEAP).

Esta última ação, o NEAP, foi pensada como uma 'meta-atividade' que agregaria todo o planejamento e gestão do projeto, possibilitando que estudantes participassem de todo o processo constitutivo, especialmente na Administração Pública, sendo, ao mesmo tempo, o espaço de gestão do NAP e um laboratório de gestão dentro de um projeto de extensão. A equipe foi composta pelo estudante proponente, duas voluntárias e uma bolsista remunerada. A modalidade de protagonismo estudantil não condiciona obrigatoriedade do/da proponente tornar-se bolsista com remuneração, permitindo a abertura dos processos seletivos para esta vaga. No caso do NAP, foram solicitadas duas bolsas, porém foi obtida apenas uma.

Vale ressaltar que, antes de iniciar o projeto, surgiram alguns entraves, os quais foram facilmente superados: após uma leitura mais cuidadosa do edital, estudantes verificaram que era permitido à discente unicamente a proposição do projeto (e não a coordenação dele), havendo a necessidade de uma/um professora/professor tutor/a.

Ademais, como o NAP estava intrinsecamente ligado ao PIE "Trabalho, Renda e Economia Solidária", significava consequentemente a existência de uma relação hierarquizada, na qual o coordenador geral do PIE automaticamente tornava-se responsável pelos projetos aprovados na modalidade PROPE em suas linhas de atuação. Isto, inicialmente, levantou dúvidas sobre como os objetivos traçados pelo NAP se correlacionavam com o PIE e de que forma o PIE se relacionaria com o NAP.

Após alguns diálogos esclarecedores, um professor tutor foi designado ao projeto e as relações com a coordenação do PIE ficaram acertadas, sendo mais facilitadas porque, em ambos os casos, se tratavam de docentes do bacharelado em Administração Pública que também tinham uma forte estima com os integrantes do NAP. Deste modo, na teoria, o NAP 
ficaria submetido a algum professor tutor e os estudantes atuariam como auxiliares do projeto, sendo o protagonismo do edital apenas na proposição do projeto. Dado o voto de confiança pelos docentes, o NAP, na prática, detinha o estudante proponente como coordenador das ações e os professores, tanto o tutor como o coordenador do PIE, atuavam como assessores e somente quando provocados pelos próprios membros do NAP.

Sanadas as dúvidas, novos desafios foram postos ao planejamento das ações: aproximar servidores e servidoras técnicas da universidade com o curso de Administração Pública, por meio da programação do NAP, convidando a compartilharem suas vivências e seus principais desafios na gestão pública federal. Indiretamente, essa aproximação possibilitava a estudantes a compreensão de que, além de um ambiente de ensino superior, a UFCA é também um laboratório de práticas de gestão pública federal e que o curso possui abertura para com os demais setores da universidade.

As primeiras ações do NAP ocorreram em abril de 2017, com a organização do "I Ciclo Temático do Núcleo de Atualização Pública: Introdução às Políticas Públicas \& Atualidades". Neste ciclo, foram idealizados quatro eventos. Nas terças-feiras, no turno da tarde, foram realizados três minicursos: 1) O Cinturão das Águas do Ceará e os efeitos de um planejamento centralizado; 2) Planejamento, gestão e vivência: os desafios e perspectivas do planejamento institucional da UFCA; e 3) Economia Solidária: conceitos teóricos e práticas institucionais.

Quanto aos eventos, ocorreu o "I Encontro com Gestores: os bastidores da Política Pública", buscando a partilha de experiências de gestores e ex-gestores públicos na Administração Pública. Ao final de cada ação, foi realizada uma avaliação de satisfação com o intuito de mapear a qualidade das ações propostas, sugestões de temáticas, melhorias e críticas em geral. 
Foto 1: Minicursos e eventos do I Ciclo Temático do Núcleo de Atualização Pública: Introdução às Políticas Públicas \& Atualidades referentes ao mês de abril.

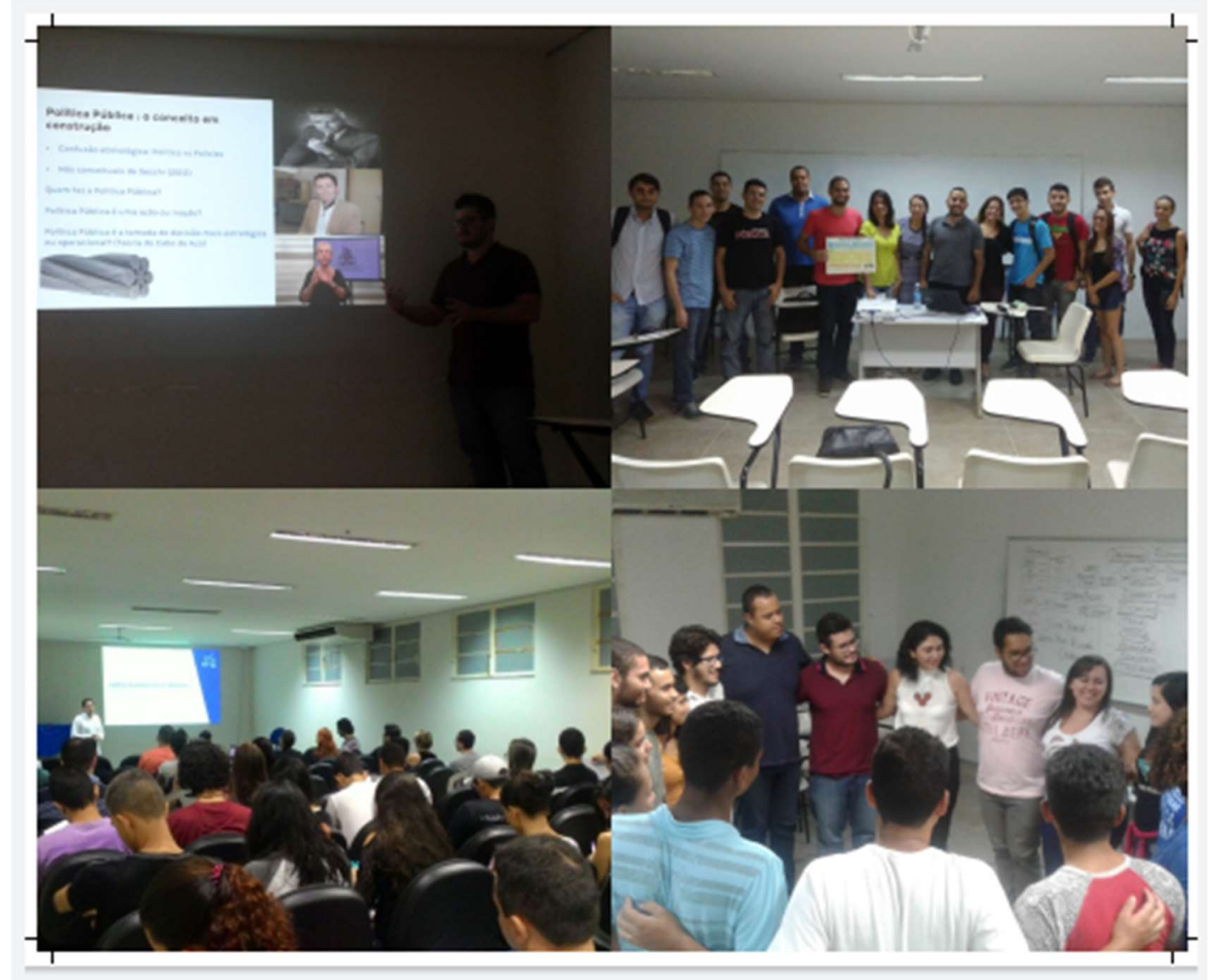

Fonte: Acervo do NAP.

No mês de maio, para o II Ciclo temático, foi escolhida a própria instituição como tema central, sendo intitulado como "II Ciclo Temático do NAP: UFCA - universidade e espaços de experiência gerencial”. Em parceria com o Escritório Habitar (Projeto de extensão da UFCA, ligado ao curso de Engenharia Civil, que promove assessoria e elaboração de projetos para famílias de baixa renda na Região do Cariri Cearense), o NAP desenvolveu o "Curso de Licitações e Contratos", o qual foi ministrado pelo coordenador e pregoeiro da Coordenação de Licitação da Pró-Reitoria de Administração da UFCA.

Além desta ação, o NAP desenvolveu o curso "Transparência e Governança: incentivando boas práticas de gestão" e o II Encontro com Gestores com a seguinte temática: "Desafios e perspectivas da avaliação institucional da UFCA", ambos executados por servidores da UFCA. 
Dada a complexidade do Curso de Licitações e Contratos - com duração de quatro dias -, não ocorreram os demais minicursos tradicionalmente às terças-feiras, exceto com a temática de transparência e governança. É possível que a alteração da periodicidade dos cursos às terças-feiras (tal como o mês de abril) tenha rompido o fluxo recorrente de alunos, sendo o de transparência e governança o de menor presença estudantil (em média, 7 a 9 discentes).

Foto 2 - Minicursos e eventos do II Ciclo Temático do Núcleo de Atualização Pública: UFCA universidade e espaços de experiência gerencial.

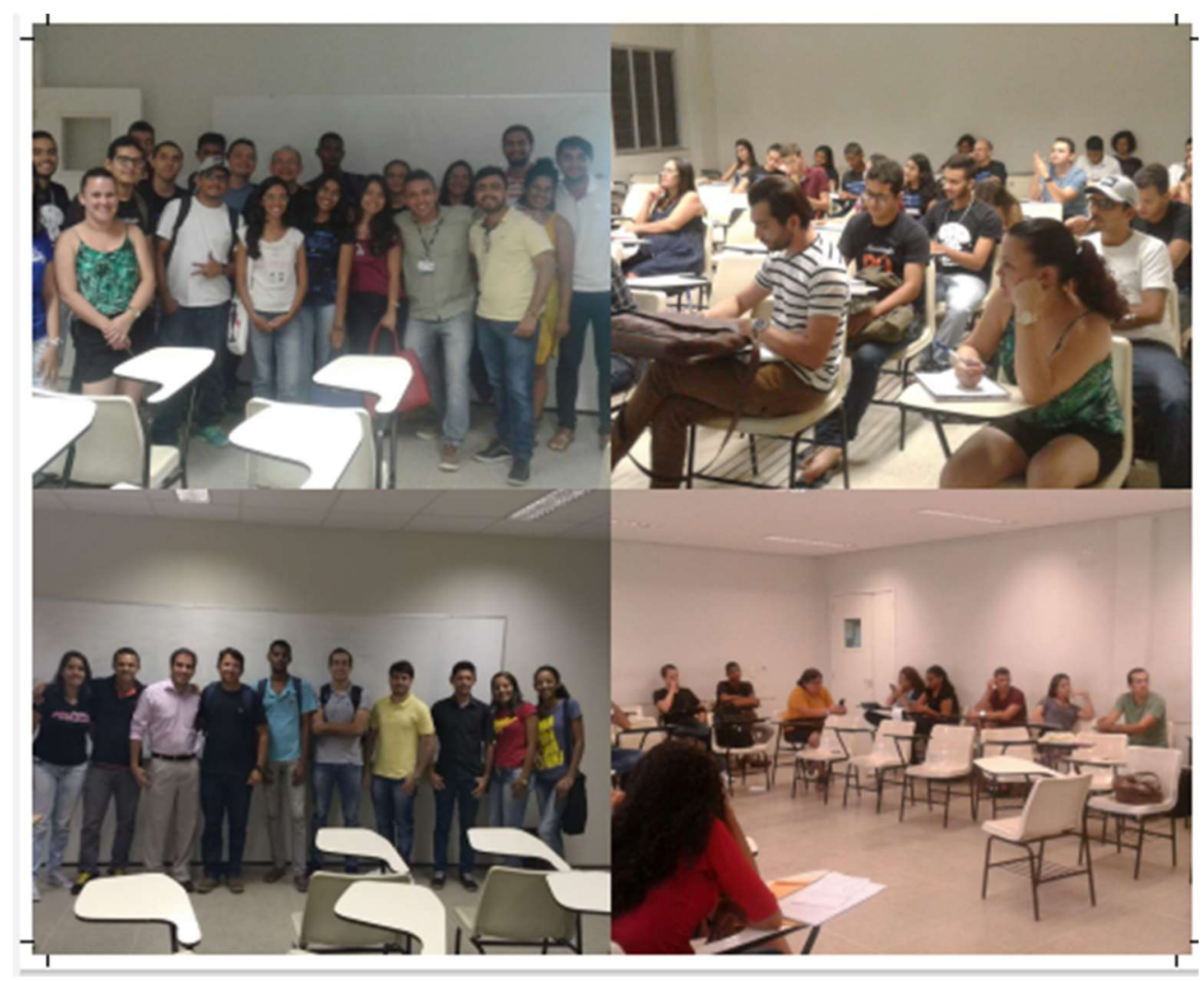

Fonte: Acervo do NAP.

Enquanto suas atividades eram desenvolvidas, o NAP possibilitou o processo de inserção de novos participantes do curso de Administração Pública, por meio da residência social em núcleo de conhecimento - nomenclatura própria do Campo de públicas para a modalidade análoga ao estágio acadêmico em atividades de extensão. Nessa modalidade, o projeto recepcionou duas discentes e as inseriu em todos os processos de integração, planejamento, tomada de decisão, gestão e avaliação, tornando-se assim um ambiente dialógico e flexível, permitindo a todos opinarem sobre as ações e adaptarem seu tempo à realização das atividades propostas. 
Dentre as principais dificuldades, integrantes do NAP passaram por uma fase de desmotivação, pois após o final do primeiro semestre letivo houve um baixo índice de participação, gerando dúvidas sobre o andamento e futuro do projeto. Não obstante, mesmo com os avanços, o grupo notou que carecia de certas condições que ampliassem a programação, aumentassem e diversificasse a adesão do público (por vezes, se concentrava em estudantes da UFCA, especialmente da Administração Pública). Atividades como "Figura Pública" foram arquivadas pela falta de conhecimento de estudiosos que investigassem determinadas personalidades.

Os problemas se acentuaram quando o proponente do NAP concluiu sua graduação no primeiro semestre de 2017, em junho. Sua saída encerrou seu vínculo com a UFCA, ocasionando o consequente desligamento com as atividades do NAP e a estagnação das ações do projeto. Verifica-se apenas em outubro daquele ano uma nova ação: o curso "A importância do Currículo Lattes para o profissional do Campo de Públicas, inserindo e atualizando a plataforma", que foi ministrado por uma egressa do curso e que, infelizmente, obteve também um baixo número de participantes. Após isso, as ações foram interrompidas, tornando a bolsista do NAP um membro suporte das atividades do PIE.

A paralisação das atividades se deu principalmente pela inexperiência dos integrantes do NAP em gestão, onde o planejamento tornou-se demasiadamente flexível e de curto alcance, tendo em vista que não havia um cronograma sólido anual. Logo, o planejamento se limitava ao horizonte mensal, mas não era projetado para eventualidades inesperadas (ausência de palestrantes ou saída de bolsistas), o que tornava ainda mais precária a implementação de atividades. Deste modo, o projeto foi implementado e concluído no mesmo ano, em 2017.

\section{O NAP na percepção dos estudantes gestores: partilha de experiências}

Considerando a importância da formação dos gestores públicos enquanto profissionais que atuam diretamente no planejamento, elaboração e execução de políticas públicas, o contato com ações de extensão que estimulam o protagonismo estudantil possibilita aos discentes a construção de um perfil profissional crítico, reflexivo e interventivo. A modalidade PROPE do edital unificado, por si só inovador, ao acolher a proposta de um núcleo composto e gerido por estudantes que dialogasse diretamente com outros discentes, gerou a expectativa da inovação na oferta de atividades extensionistas nas quais a sua participação proporcionaria, talvez, o preenchimento de lacunas nas exposições de conteúdos presentes na sala de aula ou abordaria temas transversais do ensino.

A experiência foi bastante válida, despertando inclusive o interesse pela área de planejamento e gestão de projetos. Para estudantes que desejassem desenvolver algum tipo de ideia que gerasse transformação social, mas não sabiam por onde começar, o edital PROPE foi ideal para entender como pensar, formular, escrever e desenvolver um projeto de extensão. Além disto, acreditamos que a experiência do NAP se destacou das demais, pois o voto de confiança dos docentes permitiu que os alunos desfrutassem de vitórias por um evento bem 
sucedido, bem como amargurar com um planejamento malsucedido, mas que, em ambos os casos, foram experiências riquíssimas.

A experiência inicial proporcionada pelo edital PROPE possibilitou que novos projetos fossem pensados e elaborados, mas agora em uma ótica muito mais profissional, como foi o caso do projeto "Gabinetes Profissionais do Ceará", onde foi possível apresentar uma proposta para membros do legislativo estadual visando a profissionalização e inserção de gestores profissionais nos cargos de assessoria parlamentar.

Um dos entraves que possivelmente dificultaram a atração de novos públicos para o projeto consistiu na localização da universidade: distante do centro da cidade e de difícil acesso. Tal dificuldade talvez fosse superada por meio de parcerias com outras instituições de ensino ou escolas localizadas mais próximas do centro da cidade, ampliando organizações no projeto e diversificando mais o público interessado, além de uma maior divulgação das ações do NAP, muitas vezes isolada em um pequeno círculo de alcance.

Mesmo com as adversidades e com um grupo com equipe reduzida, porém totalmente engajada no projeto e na busca da sua execução com excelência, o projeto possibilitou o desenvolvimento de potencialidades e competências individuais, tais como a autogestão e autonomia, ambos frutos do protagonismo estudantil.

\section{Conclusão}

A modalidade de protagonismo estudantil encontrada no Edital 01/2017 (PROEX/ UFCA) é bastante inovadora, pois atribui uma postura de proatividade ao estudante, distinto dos demais projetos em que, muitas vezes, os estudantes são apenas operadores de um projeto já desenvolvidos por algum professor ou técnico. A experiência foi fundamental para que os alunos do curso de Administração Pública pudessem materializar seus desejos em ter um núcleo suplementar ao curso, com formações, oficinais e palestras que buscassem demonstrar a abrangência do Campo de Públicas.

A experiência vivenciada pelo NAP se destaca das demais da modalidade PROPE, tendo em vista o voto de confiança depositado por docentes, que permitiram dar maior autonomia aos estudantes, fazendo com que aqueles ocupassem uma posição passiva, agindo apenas quando consultados. Esse sinal de credibilidade permitiu com que estudantes desenvolvessem todo o processo de planejamento, gestão e avaliação do projeto, o que inclui seus acertos e erros. Apesar das descontinuidades ocasionadas principalmente pela saída do aluno proponente e por um planejamento demasiadamente flexível, o projeto de extensão foi fundamental para despertar o desejo pelas áreas de planejamento e gestão de projetos.

Para futuras pesquisas - no âmbito da extensão universitária - recomenda-se compreender quais os impactos ou resultantes da extensão universitária na vida dos estudantes em modalidades de protagonismo estudantil e quais os impactos da vivência extensionista para estudantes recém-formadas. 


\section{Referências}

ANTUNES, Jeferson; RIBEIRO, Verônica; ARRAIS, Estêvão; MOREIRA, Raniere. A política de reestruturação e expansão das universidades federais no Brasil: Um olhar sobre o curso de Administração Pública da Ufca. In: Simpósio de Pesquisa e Inovação da UFCA, 1., 2015, Juazeiro do Norte. Anais [...]. Juazeiro do Norte: UFCA, 2015.

BRASIL. Constituição (1988). Constituição da República Federativa do Brasil. Brasília, DF: Senado Federal, 1988.

COELHO, Fernando de Souza. Educação superior, formação de administradores e setor público: um estudo sobre o ensino de administração pública, em nível de graduação no Brasil. Tese (Doutorado em Administração Pública e Governo) - FGV - Fundação Getúlio Vargas, São Paulo, 2006.

CRESWELL, John W. Projeto de pesquisa métodos qualitativo, quantitativo e misto. Porto Alegre: Artmed, 2010.

DCN. Diretrizes Curriculares Nacionais. Resolução n. ${ }^{\circ}$ 4, de 13 de julho de 2005. Conselho Nacional de Educação, Câmara de educação superior. 2005. Disponível em: http://portal.mec.gov.br/cne/arquivos/pdf/rces004_05.pdf. Acesso em: 13 set. 2020.

FLICK, Uwe. Introdução a pesquisa qualitativa. 3. ed. Porto Alegre: Artmed, 2009.

LIANZA, S. et al. Gestão de projetos solidários: o coração do Soltec. In: ADDOR, F.; $\angle I A N Z A, S$. (org.). Percursos na extensão universitária: saindo da torre de marfim. Rio de Janeiro: Editora UFRJ/FAPERJ, 2015. p.21-36.

PIRES, Valdemir Aparecido et al. Dossiê campo de públicas no Brasil: definição, movimento constitutivo e desafios atuais. Administração Pública e Gestão Social, v. 6, n. 3, p. 109-167, 2014.

UFCA. Edital 01/2017. Disponível em: https://documentos.ufca.edu.br/wp-folder/wpcontent/uploads/2019/09/PROEX-UFCA-Edital-N\%C2\%BA-01-2017-PROPE-201717.01.2017.pdf. Acesso em: 8 set. 2020.

UFCA. Você já conhece os PIEs? 2020. Disponível em: https://proex.ufca.edu.br/voce-jaconhece-os-pies/. Acesso em: 28 ago. 2020. 